\title{
O fundamento como "fundamento ausente" nas ciências sociais: Heidegger, Derrida e Laclau
}

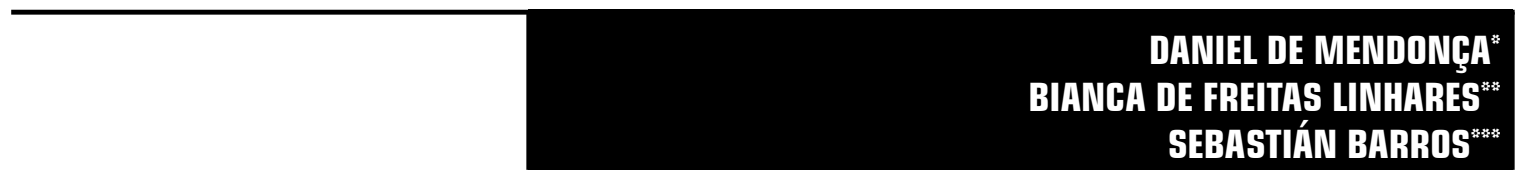

\section{Resumo}

Neste artigo, refletimos teoricamente sobre o pós-fundacionalismo, corrente filosófica que influenciou o surgimento do pós-estruturalismo francês na segunda metade do século XX. De uma forma mais específica, nosso objetivo é discutir as implicações ontológicas, teóricas e epistemológicas da abordagem pós-fundacional para pesquisas em ciências sociais. Para tanto, cumprimos o seguinte percurso. Primeiramente, discorremos sobre o que chamamos de o Zeitgeist pós-fundacionalista, em especial a ênfase na diferença ontológica e no fundamento como Abgrund oriundos da obra de Martin Heidegger. A seguir, apresentamos a influência heideggeriana na reflexão filosófica pós-estruturalista de Jacques Derrida. Na sequência, discutimos a incorporação e a aplicação da ontologia heideggeriana na obra de Ernesto Laclau, principalmente a partir da discussão das noções de hegemonia e de populismo. Ao final, apresentamos nossas considerações acerca da importância do pós-fundacionalismo para pesquisas na área das ciências sociais.

Palavras-chave: Pós-fundacionalismo. Pós-estruturalismo. Abgrund. Ontologia. Epistemologia.

\footnotetext{
* Universidade Federal de Pelotas (Brasil).

** Universidade Federal de Pelotas (Brasil)

*** Universidade Nacional da Patagônia San Juan Bosco (Argentina).
} 
Sociologias, Porto Alegre, ano 18, no 41, jan/abr 2016, p. 164-194

\section{The foundation "without foundation" in social sciences: Heidegger, Derrida and Laclau}

\section{Abstract}

This article presents a theoretical reflection on the post-foundationalism, a philosophical school that furthered the rising of French post-structuralism in the second half of the $20^{\text {th }}$ century. It aims, particularly, to discuss the ontological, theoretical and epistemological implications of the post-foundational approach for researches in Social Sciences. To this end, first, the authors' understanding of what they call post-foundationalist Zeitgeist is discussed, especially the emphasis on the ontological difference and on foundation as Abgrund, according to Martin Heidegger's work. Second, the Heideggerian influence on Jacques Derrida's post-structuralist philosophical thought is presented. After that, the incorporation and use of Heideggerian ontology in the work of Ernesto Laclau is discussed, focusing on the notions of hegemony and populism. The article ends with considerations on the importance of post-foundationalism for social sciences researches.

Keywords: Post-foundationalism. Post-structuralism. Abgrund. Ontology. Epistemology.

Mas somente se nos voltarmos pensando para o já pensado, seremos convocados para o que ainda está para ser pensado. Martin Heidegger

\section{Introdução}

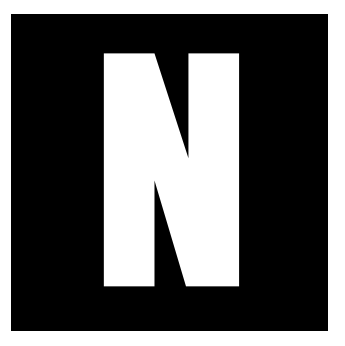

este artigo, refletimos teoricamente sobre o pós-fundacionalismo, corrente filosófica que influenciou o surgimento do pós-estruturalismo francês na segunda metade do século vinte. De forma mais específica, nosso objetivo é discutir as implicações ontológicas, teóricas e epistemológicas da abordagem pós-fundacional para pesquisas em ciên- 
cias sociais. Para tanto, cumprimos o seguinte percurso. Primeiramente, discorremos sobre o que chamamos de o Zeitgeist pós-fundacionalista, em especial a ênfase na diferença ontológica e no fundamento como Abgrund oriundos da obra de Martin Heidegger. A seguir, apresentamos a influência do filósofo alemão na reflexão filosófica pós-estruturalista de Jacques Derrida. Na sequência, discutimos a incorporação e a aplicação da ontologia heideggeriana na obra de Ernesto Laclau, principalmente a partir da discussão das noções de hegemonia e de populismo. Ao final, apresentamos nossas considerações acerca da importância do pós-fundacionalismo para pesquisas na área das ciências sociais. Comecemos, portanto, caracterizando o Zeitgeist pós-fundacional.

Talvez, uma das maiores dificuldades que podemos encontrar ao fazer uma análise crítica das perspectivas filosóficas e científicas fundacionalistas seja o fato de que, ao fazê-la, estamos como que abrindo uma caixa de Pandora. Qualquer crítica ao fundamento é, ao mesmo tempo, uma crítica à verdade, à origem, ao transcendente, ou seja, ao(s) chão(s) que, de forma segura, pisaram e ainda pisam filósofos e cientistas. Ainda que saibamos que as histórias do conhecimento e do conhecimento científico sejam pródigas em fundamentos não raramente antagônicos entre si (Deus, natureza, homem, razão etc.), a própria ideia de fundamento é praticamente não contestada.

Além de ser uma tarefa difícil, ela tem tudo para ser igualmente inglória. Não basta falarmos "contra" o fundamento simplesmente como a negação da sua existência, num sentido antifundacionalista. O erro de uma empreitada como esta, tal como foi observado por Marchart (2007), é que negar tout court a existência do fundamento redunda necessariamente em erigir outro fundamento final na figura do "antifundamento". Nesse sentido, os antifundacionalistas teriam de aceitar que é impossível superar o fundacionalismo. 
A solução para uma crítica ao fundacionalismo não está, entendemos, na negação do fundamento como tal, mas no enfraquecimento ontológico dos fundamentos existentes. Isso quer dizer que, se por um lado, não temos por que negar - tampouco essa seja a nossa intenção - a presença de fundamentos, podemos, por outro lado, argumentar contrariamente à ideia de um fundamento último para o que quer que seja. Ademais, nosso argumento central consiste na ideia de que há tantos fundamentos parciais, seja na filosofia, seja na ciência (como vimos Deus, natureza, homem, razão etc.), justamente pelo fato de não haver um fundamento último ou transcendental. Tal inexistência resulta igualmente produtiva ao pensamento humano. Assim, não há um fim para a história, pois a história não tem verdadeiramente um fim e justamente esse não fim é o que permite haver história.

A perspectiva filosófica que adotamos na presente análise é chamada de pós-fundacionalista (Marchart, 2007), pois supõe a impossibilidade de um fundamento último. Dessa maneira, insistimos, não se trata de negar o fundamento, mas de dar a ele um status completamente diferente ao que the tem sido comumente atribuído pelas mais distintas perspectivas fundacionalistas. O fundamento, como veremos, é a ausência de fundamento; o fundamento é, como argumenta Martin Heidegger (2006, 2007), um Abgrund, um abismo, um afundamento, um sem-fundo.

Mas qual seria a importância de discutirmos criticamente o fundamento a partir da perspectiva pós-fundacional? Por que seria relevante pormos em suspenso os limites de todo e qualquer fundamento? Tais perguntas, longe de serem retóricas, conduzem-nos a respostas que dão a imagem de um tempo, do nosso tempo. Tempo de contestação de verdades pré-estabelecidas, de desnaturalização, de reativação de sedimentos, de descentramentos estruturais: vivemos em um Zeitgeist desconstrutivo no sentido derridiano do termo. 
Os pensamentos filosófico e das ciências sociais, sobretudo franceses, sofreu, na segunda metade do século passado, grande influência do pós-fundacionalismo, principalmente heideggeriano. Dificilmente poderíamos falar na desconstrução operada por Jacques Derrida sem considerarmos a Destruktion da metafísica de Heidegger. Assim, pensar mais amiúde acerca do pós-estruturalismo francês não requer somente conhecermos suas origens no estruturalismo, primeiramente linguístico desde Saussure (2006), passando Claude Lévi-Strauss (2012), mas também é preciso levarmos em consideração que o pós-estruturalismo - que é a própria desconstrução do estruturalismo - somente foi possível pela fundamental influência que Heidegger exerceu sobre o pensamento de Jacques Derrida (e de outros), como veremos mais adiante.

Contudo, queremos deixar claro, desde já, que, de forma alguma, estamos propondo uma leitura homogênea dos filósofos e dos cientistas sociais que têm em comum abordagens críticas ao que acima caracterizamos como fundacionalismo. Daí há pouco termos nos referido ao fato de que estamos testemunhando um tempo de críticas - sociais, políticas, culturais, científicas, filosóficas - às mais diversas verdades dispersas nesses campos. Questionamentos que têm sido acompanhados por diversos "pós": pós-estruturalismo, pós-modernismo, pós-marxismo, pós-colonialismo. Entendemos que as imprecisões e incertezas que marcam nosso tempo metaforizado por tantos "pós" podem ser mais bem percebidas se "encontrarmos" a sua origem não originária, o seu fundamento abissal. Certamente um dos principais expoentes desse Zeitgeist seja Martin Heidegger e o seu projeto de destruição da metafísica. 


\section{Heidegger: o abismo como fundamento, o fundamento como abismo}

A discussão sobre a noção de fundamento em Heidegger está centralmente ligada à mais importante temática desenvolvida por esse filósofo: aquela que se relaciona com o sentido do ser. Uma primeira particularidade, que desde já nos cabe mencionar, é que o ser heideggeriano nunca está apartado do mundo, tal como na tradição cartesiana (podendo-se, a partir desta última, estabelecer uma nítida diferença e distância entre sujeito e objeto). O ser em Heidegger somente é ser porque é literalmente um ser-aí (Dasein), um ser jogado no mundo. Mas em que sentido, para Heidegger, fundamento e ser fazem parte de uma e mesma discussão? Para esta questão, há dois elementos que devem ser considerados. Primeiramente, o fato de que a discussão metafísica - grosso modo entendida como a ciência primeira que define o princípio (fundamento) que condiciona a validade dos demais (Abbagnano, 2000) - já é, em Aristóteles, uma discussão ligada à ontologia, ou seja, a da reflexão do ser como tal. O segundo elemento, propriamente heideggeriano, liga-se ao tratamento não essencialista que o filósofo deu ao ser e ao fundamento, que, como veremos nessa seção, refere-se ao fundamento "inessencial" ou abissal do ser.

A discussão sobre ser e fundamento em Heidegger é imensa e pode ser tratada desde perspectivas e entradas diferentes em sua filosofia. Não é nosso objetivo tratá-la além do que é necessário para avançar no ponto central de nosso artigo, qual seja, a influência decisiva do filósofo alemão para o pensamento pós-fundacionalista que, como vimos, será fundamental à compreensão do pós-estruturalismo francês.

Nesse sentido, iniciaremos pela tarefa destruidora da filosofia heideggeriana presente em "Ser e Tempo" (2002). No parágrafo sexto, intitulado "A tarefa de uma destruição da história da ontologia", Heidegger discorre sobre o projeto da Destruktion da ontologia tradicional: 
Sociologias, Porto Alegre, ano 18, no 41, jan/abr 2016, p. 164-194

Caso a questão do ser deva adquirir a transparência de sua própria história, é necessário, então, que se abale a rigidez e o endurecimento de uma tradição petrificada e se removam os entulhos acumulados. Entendemos essa tarefa como destruição do acervo da antiga ontologia, legado pela tradição. Deve-se efetuar essa destruição seguindo-se o fio condutor da questão do ser até se chegar às experiências originárias em que foram obtidas as primeiras determinações do ser que, desde então, tornaram-se decisivas (2002, p. 51 - grifos do original).

Primeiramente cabe dizer que por destruição não devemos entender um empreendimento de dizimação da tradição filosófica, de sua negação in toto, mas, conforme Casanova (2015, p. 51), significa "desconstruir os encrostamentos provocados pela sedimentação dos conceitos fundamentais e liberar potencialidades que dormitam nesses conceitos mesmos". Tal desconstrução é provocada pela reativação de possibilidades silenciadas no momento em que certa decisão ou tradição foi sedimentada. A destruição é uma tarefa não somente crítica, mas positiva, visto que ela provoca a abertura de novas possibilidades de se pensar o que foi esquecido, mas também de pensar novas questões a partir do processo de reativação de sedimentos.

No caso particular da ontologia da Heidegger, a sua tarefa destruidora direcionou-se à crítica elaborada ao que é chamado de a "entificação do ser". Já na abertura de "Ser e Tempo", ele menciona a preocupação de Platão com a questão do ente, presente em "O sofista" (244a): “... pois é evidente que há muito sabeis o que propriamente quereis designar quando empregas a expressão 'ente'. Outrora, também nós julgávamos saber, agora, porém, caímos em aporia" (Heidegger, 2002, p. 24). O que o filósofo alemão quer dizer com a citação de Platão no prelúdio de sua obra é que a questão ontológica, ou seja, a da "doutrina do ser" (Heidegger, 2013, p. 7), é um problema que tem origem já na filosofia grega clássica e 
que persiste ao longo de toda a história da filosofia. Assim, revisitar a problemática do ser desde a destruição da ontologia tradicional foi o objetivo primordial da obra de Heidegger.

Como dissemos acima, para o filósofo alemão, pensar acerca do ser requer que pensemos sobre o fundamento do ser, mas também sobre a ideia do fundamento enquanto tal. A ideia central, nesse sentido é a da diferença ontológica a qual é, por exemplo, em "A essência do fundamento", entendida como "o Não entre o ente e o Ser" (Heidegger, 2007, p. 7). Mas o que isso significa? Significa que entre os planos ôntico (dos entes) e ontológico (do ser) existe um afundamento, um abismo (Ab-grund). Nesse sentido, o insight mais fundamental de Heidegger foi justamente o de concluir que a história da ontologia nunca se deparou diretamente com uma reflexão acerca do ser, mas, ao contrário, esta cuidou de entificá-lo, ou seja, atribuindo ao ser características de entes (essência, substância, razão, identidade etc). Contrariamente, o projeto heideggeriano da ontologia fundamental, por um lado, visa destruir essa entificação histórica do ser e, por outro lado, dar lugar a um pensamento que não encontre uma identidade (que não existe) no ser, mas que reflita sobre ele sem incorrer novamente em sua entificação.

Assim, para Heidegger, o ser é fundamentalmente sem essência, sem substância. O ser não é o homem, mas o homem está "inserido no ser" (2006, p. 44). Dessa forma, ser e homem (ente) são distintos e separados, tal como a dimensão ontológica é em relação à ôntica. A única essência possível do ser é a sua própria existência. O fundamento do ser é não ter qualquer fundamento ou o abismo (Abgrund) é o fundamento do ser. Segundo Heidegger (2000, p. 80-81):

Ser e fundamento pertencem um ao outro de modo concomitante. A partir da sua copertença com o ser enquanto ser, o fundamento recebe a sua essência. Inversamente, o ser enquanto ser rege a partir da essência do fundamento. 
Fundamento e ser ("são") o mesmo, não o igual, o que logo a diferença dos nomes "ser" e "fundamento" indica. Ser "é" na essência: fundamento. Por isso o ser nunca pode anteriormente ter um fundamento, que o deva fundamentar. Em consequência disto o fundamento do ser permanece fora. $\mathrm{O}$ fundamento permanece fora do ser. No sentido de um tal permanecer-fora do (Ab-bleibens) fundamento do ser, "é" o ser o sem-fundo (Ab-Grund). Na medida em que o ser enquanto tal é fundamentado em si próprio, permanece ele mesmo sem fundamento.

O que a citação acima sugere? Primeiramente que há uma relação de unidade entre ser e fundamento. No entanto, ainda que haja tal relação entre ambos, eles não são iguais, visto a própria existência dos nomes "ser" e "fundamento". Após, mais uma relação, esta crucial: "Ser "é" na essência: fundamento". Esse ponto é central para o argumento que desenvolveremos na sequência deste artigo, pois, ao contrário do que pressupõem perspectivas anti fundacionalistas, Heidegger não abre mão do fundamento, ele não nega a metafísica. Na sequência: o ser não pode ter um fundamento que o fundamente, no sentido de este fundamento estar fora do ser, além do ser, comandar "de fora" o ser, tal como nas ontologias históricas que o entificaram. Se o fundamento não está fora, mas no ser, se o ser é essencialmente fundamento, ergo o ser é "sem-fundamento", é "abismo", ou o abismo é o fundamento e o fundamento é o abismo, conforme Heidegger. É nesse sentido que Rée (2000, p. 18) afirma que a "ontologia fundamental irá dissolver fundações ontológicas e revelar que nossa existência não tem nenhuma base senão ela mesma".

De que forma a digressão acerca da relação entre ser e fundamento em Heidegger pode nos ser útil para pensarmos as ciências sociais desde um ponto de vista pós-fundacional? Antes de chegarmos nesse ponto, precisamos passar pela recepção da filosofia heideggeriana no cenário (pós)estruturalista francês da segunda metade do século XX: a desconstrução de Jacques Derrida. 


\section{Jacques Derrida: a estrutura como fundamento último}

A intuição heideggeriana de que não há substância ou essência fora do ser que determine o seu fundamento foi decisiva para o surgimento do pós-estruturalismo, este último entendido como um momento de desconstrução do estruturalismo. O pós-estruturalismo não foi, assim como o próprio estruturalismo, um movimento unificado ou uma escola de pensamento ${ }^{1}$. Constituiu-se, antes, em uma forma de pensar, calcada no exercício desconstrucionista de reativação de estruturas sedimentadas ou calcificadas. Sob formas e campos diversos das humanidades, esse novo espírito, oriundo, insistimos, das próprias "entranhas" do estruturalismo, dominou o cenário principalmente francês na segunda metade do século XX. Não estamos afirmando, de forma categórica, que os pós-estruturalistas são "herdeiros" de Heidegger, mas que "o pós-estruturalismo" incorporou, de forma mais acabada, o Zeitgeist pós-fundacional do século passado, o qual segue existindo ainda neste princípio de $X_{X I^{2}}$. Vejamos esta longa, porém, elucidativa passagem de um texto de Jacques Derrida (2002, p. 232), considerado um artigo clássico e "fundador" do pós-estruturalismo:

Onde e como se produz esse descentramento como pensamento da estruturalidade da estrutura? Para designar esta produção, seria de certo modo ingênuo referir um acontecimento, uma doutrina ou o nome de um autor. Esta produção pertence sem dúvida à totalidade de uma época, que é a nossa, mas ela sempre já começou a anunciar-se

\footnotetext{
${ }^{1} \mathrm{O}$ pós-estruturalismo tem sido uma forma de pensamento rica de grandes expoentes. Ainda que alguns pensadores rejeitem o rótulo "pós-estruturalista", podemos identificar, tendo em vista a leitura crítica do essencialismo estruturalista, além de Jacques Derrida, Gilles Deleuze, Jean-François Lyotard, Michel Foucault, Julia Kristeva, entre outros (Williams, 2013).

${ }^{2}$ Sobre a influência de Heidegger no pensamento filosófico francês no século XX, Oliver Marchart (2007) argumenta a respeito da existência de um "heideggerianismo de esquerda" (Left Heideggerianism) presente nas obras dos franceses Jean-Luc Nancy, Claude Lefort e Alain Badiou, além de na obra do filósofo argentino Ernesto Laclau, cuja influência de Heidegger apresentaremos na sequência deste artigo.
} 
e a trabalhar. Se quiséssemos, contudo, a título de exemplo, escolher alguns "nomes próprios" e evocar os autores dos discursos nos quais esta produção se manteve mais próxima da sua formulação mais radical, seria sem dúvida necessário citar a crítica nietzschiana da metafísica, dos conceitos de jogo, de interpretação e de signo (de signo sem verdade presente); a crítica freudiana da presença a si, isto é, da consciência, do sujeito, da identidade a si, da proximidade ou da propriedade a si; e, mais radicalmente, a destruição heideggeriana da metafísica, da onto-teologia, da determinação do ser como presença.

Notemos que, a despeito de suas diferenças, o que há de comum entre Nietzsche, Freud e Heidegger, é o que poderíamos chamar de, para usar um termo caro a Derrida, a crítica à metafísica da presença, ou seja, o questionamento das figuras dos fundamentos imóveis, essenciais, os quais fizemos referência na seção anterior. Tal crítica pode ser grosso modo chamada de pós-fundacionalista, a qual, como vimos, ainda que não negue a existência de fundamentos parciais, parte do pressuposto de que o único fundamento possível é o próprio não fundamento, ou seja, uma falta constitutiva que permite a existência de fundamentos parciais. De fato, falar em falta constitutiva é se remeter à ideia heideggeriana de fundamento como Abgrund. Para Heidegger, como o ser é essencialmente sem fundamento, ou, como também vimos, o ser é fundamento, ele é livre, tem "liberdade para o fundamento" (Heidegger, 2007, p. 115). Isso, porém, não quer dizer que o ente tem "um mundo de possibilidades infinitas pela frente", como, a princípio poderia ser sugerido. O Dasein é literalmente lançado aí; é uma existência em um mundo que a preexiste. Não há, portanto, infinitas escoIhas para ele, ao mesmo tempo em que não há qualquer fundamento transcendente (além do não fundamento último, é claro) que essencialmente e necessariamente guie suas ações. Isso supõe, consequentemente, que este ente pode tomar decisões de acordo com o mundo que, em sua existencialidade, o circunda, o limita, o estrutura. 
Tal intuição heideggeriana é central à desconstrução do projeto da cientificidade fundacional do estruturalismo levada a efeito por Jacques Derrida. Em termos gerais, o filósofo francês argumenta, de modo muito similar a Heidegger e, claro, contrariamente aos estruturalistas, em torno da inexistência de fundamentos transcendentais a uma estrutura, os quais ele chama genericamente de centro. Se o centro (fundamento) de uma estrutura não entra no jogo da estruturalidade, ele não é de fato um centro, mas um fundamento além da estrutura. Para o centro ser interior à estrutura, ele deve estar adstrito às regras da estrutura, o que não é o caso no contexto do estruturalismo. A crítica derridiana ao centro estruturalista pode ser aplicada, por exemplo, a este excerto do texto "Estruturalismo e crítica", de Claude Lévi-Strauss (1968, p. 393):

Em antropologia, como em linguística, o método estrutural consiste em descobrir formas invariantes no interior de conteúdos diferentes. A análise estrutural, a que indevidamente recorrem alguns críticos e historiadores da literatura, consiste, ao invés, em procurar sob as formas variáveis conteúdos recorrentes. Surgiu, por isso, já um mal-entendido: sobre a relação entre substância e forma e sobre a relação entre conceitos distintos como os de recorrência e de invariante, o primeiro ainda aberto à contingência, enquanto o segundo se funda na necessidade.

É bem conhecido o objetivo do projeto estruturalista de dotar cientificidade e certeza ao conhecimento produzido pelas ciências humanas. $\mathrm{O}$ interesse de Lévi-Strauss, ou seja, o de "descobrir formas invariantes no interior de conteúdos diferentes" a partir dos achados de Ferdinand de Saussure (2006) e seguidores, era a aposta de, primeiramente na antropologia cultural, encontrar fundamentos sólidos capazes de conduzir os cientistas sociais, enfim, na direção da produção de um conhecimento sólido, apto a, a exemplo das ciências duras, estatuir leis gerais, verdades últimas, fundamentos permanentes. Lévi-Strauss, conforme Dosse (2007), tinha particular 
interesse pela fonologia, pelo fato de que esta subárea da linguística ia além dos fenômenos linguísticos conscientes, introduzindo, para tal, a noção de sistema, a fim de extrair leis gerais. Mutatis mutandis, foi justamente o que fez o pai da antropologia estrutural com a enunciação da lei da "proibição do incesto", uma norma universal a despeito da enorme diversidade que envolve as sociedades humanas (Lévi-Strauss, 2012).

O projeto de cientificidade estruturalista é apenas mais um capítulo, na história do conhecimento humano, que visa encontrar fundamentos, leis universais, verdades últimas. No entanto, tal projeto, iniciado como uma crítica viceral do humanismo existencialista de Sartre (Dosse, 2007), por volta do início da década de 1950, teve a sua existência - que prometia uma vida longa pela "verdade científica" que portava - em parte bruscamente interrompida, se considerarmos a sua forma original. Dissemos "em parte", pois a leitura desconstrucionista do pós-estruturalismo nunca pretendeu ir "além" das estruturas. Pelo contrário, para os pós-estruturalistas, mantêm-se os fundamentos (parciais), porém abandonam-se as essências, os fundamentos transcendentes, os centros imóveis. É justamente essa a ideia expressa no texto derridiano provavelmente mais emblemático com relação à desconstrução do primado estruturalista, "A estrutura, o signo e o jogo no discurso das ciências humanas". "Centro", como dissemos, deve ser entendido como fundamento "na estrutura e fora da estrutura" (Derrida, 2002, p. 230). Na sequência, Derrida afirma:

O conceito de estrutura centrada é com efeito o conceito de um jogo fundado, constituído a partir de uma imobilidade fundadora e de uma certeza tranqüilizadora, ela própria subtraída ao jogo. A partir desta certeza, a angústia pode ser dominada, a qual nasce sempre de uma certa maneira de estar implicado no jogo, de ser apanhado no jogo, de ser como ser logo de início no jogo (2002, p. 230-231 grifo no original). 
Angústia é um termo central no contexto da passagem acima, mas também, e fundamentalmente, em nossa discussão como um todo. Como vimos, Derrida opõe a "estrutura centrada", o "jogo fundado", a "imobilidade fundadora", a "certeza tranqüilizadora", à angústia. Esta última resulta no que chamaremos de a "possibilidade da impossibilidade", resumida na seguinte questão, esta dirigida aos defensores do fundacionalismo: e se essa certeza fundadora não puder de fato se confirmar? Assim, o princípio do fundamento como o acesso possível à verdade deriva-se justamente de uma preocupação, como vimos, histórica da metafísica de fugir da angústia causada pela incerteza da existência inequívoca de uma archè ou de um telos. Trata-se, ainda, da tentativa de dominar o futuro, de tranquilizar-se com o porvir, de caminhar longe do Abgrund, de „ser como ser logo de início no jogo", como expresso no trecho acima.

A pergunta "e se essa certeza fundadora não puder de fato se confirmar?" é própria da perspectiva fundacional, visto que, para o pós-fundacionalismo, a resposta seria clara: qualquer fundamento - alèm, é claro, do abismo - não se confirma como certeza última. Nesse sentido, segundo Abbagnano (2000), para Kierkegaard, as possibilidades do homem não têm qualquer garantia de realização, resumindo-se a radical contingência à fórmula "no possível tudo é possível". Quando o ser humano dá-se conta da infundabilidade de sua existência e de suas possibilidades, este é o momento em que, conforme Kierkegaard, ele escolhe dois caminhos: "o suicídio ou a fé, isto é, 'Aquele a quem tudo é possível'" (Abbagnano, 2000, p. 60). "Aquele", para o filósofo, é Deus, ou seja, para fugirmos do niilismo possível, gerado pela angústia, temos necessariamente de recorrer novamente a figura do fundamento último: novamente estamos diante do ser como presença. ${ }^{3}$

\footnotetext{
${ }^{3}$ Em "Ser e Tempo" (em especial no §53), Heidegger associa a angústia humana com o "ser-para-a-morte", a única inevitabilidade para qualquer existência. Para o filósofo, todas as demais situações vividas são absolutamente contingentes. O Dasein carrega em si essa inevitabilidade: "a morte é a possibilidade mais própria da presença" (\$53, 2002, p. 47), devendo-se entender: "a possibilidade mais própria, irremissível e insuperável é certa" (\$53, 2002, p. 48).
} 
Voltaremos nossa atenção neste instante para a solução de Jacques Derrida à questão do fundamento. Para ele, seguindo o espírito do tempo pós-fundacional, não há fundamento último para qualquer estrutura, também entendida como discurso, ou seja, um "sistema no qual o significado central, originário ou transcendental, nunca está absolutamente presente fora de um sistema de diferenças" (2002, p. 232). A questão derridiana, na sua crítica ao essencialismo estruturalista, lembremos, está constantemente direcionada ao status transcendental do centro; sua tarefa desconstrucionista apresenta duas possibilidades de crítica ao centro (fundamento) último: a primeira, a "hipótese clássica" e a segunda, propriamente derridiana, chamada por Oliver Marchart (2007, p. 17) de " hipótese pós-clássica". A hipótese clássica da crítica ao fundamento deve ser entendida como o esforço vão de todo discurso finito (ôntico, no sentido heideggeriano) para abarcar uma riqueza infinita. Todo discurso é finito, portanto, tendo em vista a presença de múltiplos discursos, ou seja, poderíamos entender esta finitude a partir de um "excesso", ocasionado pela multiplicidade de sentidos empiricamente existentes. Como já adiantamos, a hipótese clássica não é propriamente a alternativa derridiana à questão do fundamento, visto que a sua solução, assim a entendemos, deriva-se da diferença ontológica heideggeriana. Vejamos a partir de suas próprias palavras:

Se então a totalização não tem mais sentido, não é porque a infinidade de um campo não pode ser coberta por um olhar ou discurso finitos, mas porque a natureza do campo - a saber a linguagem e uma linguagem finita - exclui a totalização: este campo é com efeito o de um jogo, isto é, de substituições infinitas no fechamento de um conjunto finito. Este campo só permite substituições infinitas porque é finito, isto é, porque em vez de ser um campo inesgotável, como na hipótese clássica, em vez de ser demasiado grande, Ihe falta algo, a saber um centro que detenha e fundamente o jogo das substituições (Derrida, 2002, p. 244-245 - grifo no original). 
Assim, enquanto que, para a hipótese clássica, a impossibilidade do fundamento é explicada pelo excesso de sentidos, na pós-clássica, o que ocorre é justamente o oposto. Nesta última, o que impede a fundamentação (no plano ôntico) é a falta constitutiva presente em um campo finito que, por essa razão, se abre a infinitas possibilidades: se não há fundamento último, qualquer fundamento parcial é, em tese, possível. Aqui voltamos para a noção de diferença ontológica de Heidegger: se o fundamento é o abismo (Abgrund) e o abismo é o fundamento (dimensão ontológica), não há qualquer archè ou telos que defina a priori as possibilidades de fundamentação. Dito de outra maneira: se qualquer fundamento "entificante" está ontologicamente descartado, abre-se o campo para a liberdade radical de possibilidades de fundamentos. Tais possibilidades são, entendemos, auspiciosas ao desenvolvimento de pesquisas em ciências sociais, cujo um dos exemplos mais exitosos de incorporação do pós-fundacionalismo veremos na próxima seção, a partir dos elementos ontológicos centrais presentes na obra de Ernesto Laclau.

\section{Como pensar as ciências sociais sem um fundamento último?}

Nosso esforço até o momento foi o de apresentar os elementos constitutivos do pós-fundacionalismo e suas consequências ontológicas. Do que vimos até aqui, por pós-fundacionalismo devemos entender a corrente ontológica que defende a existência de fundamentos parciais (ônticos), ao mesmo tempo em que vê a impossibilidade do estabelecimento de um fundamento último (nível ontológico). Nesse sentido, a abordagem pós-fundacionalista difere-se totalmente do anti-fundacionalismo pelo fato de que este (de forma errônea, como vimos acima) nega a possibilidade de fundamentos ainda que parciais. Como vimos ainda, 
a razão de o pós-fundacionalismo prever somente a possibilidade do estabelecimento de fundamentos parciais resulta, seguindo Heidegger, da diferença ontológica entre o ôntico e o ontológico. Tal diferença foi a alternativa heideggeriana, a partir de sua reflexão ontológica, à entificação do ser presente na história da metafísica. Contrariamente a essa entificação, para o filósofo alemão, o ser não tem qualquer fundamento além do abismo (Abgrund). Isso quer dizer que o ser não pode ser apreendido por qualquer ente, pois o abismo reside justamente na distância inalcançável entre o ontológico e o ôntico.

O ponto que nos compete agora discutir pode ser resumido na seguinte questão: qual seria a colaboração possível dessa intuição filosófica heideggeriana para as ciências sociais? Nossa ideia é que radicalizar o dictum pós-fundacionalista, explorando o potencial heurístico que se abre a partir dele, pode ser extremamente produtivo para estudos sociais, culturais e políticos. Nesse sentido, certamente um dos empreendimentos teóricos contemporâneos que mais tenha avançado estrategicamente nessa direção seja a teoria do discurso da Escola de Essex, iniciada a partir das reflexões pós-estruturalistas e pós-marxistas de Ernesto Laclau e de Chantal Mouffe (Laclau e Mouffe, 1985, 1990; Laclau, 1990, 1996, 2005a, 2014). Nessa seção, veremos a forma como o pós-fundacionalismo é apropriado, principalmente por Ernesto Laclau. Exploraremos, nesse sentido, duas noções centrais de sua teoria: hegemonia e populismo.

Antes, no entanto, é preciso fazermos uma breve digressão sobre a sua categoria ontológica central: discurso. ${ }^{4}$ É somente a partir da noção de discurso que poderemos estabelecer as relações entre hegemonia e populismo e a reflexão pós-fundacional do autor. É desde já importante justificar que a reflexão laclauniana é sempre de cunho ontológico. Assim, quando

\footnotetext{
${ }^{4}$ Para um conhecimento mais detalhado de elementos constitutivos da teoria do discurso de Ernesto Laclau e de seus principais comentadores, ver, entre outros trabalhos: Torfing (1999), Howarth (2000), Mendonça e Rodrigues (2008).
} 
o filósofo argentino reflete sobre hegemonia ou populismo, não é sua intenção tratar sobre tipos ou fenômenos específicos que se remetem a essas categorias, mas sobre algo muito mais fundamental: o que é hegemonia? O que é populismo? Uma reflexão propriamente ontológica sobre ambas as noções nos permite estabelecer parâmetros não somente ontológicos, mas teóricos e epistemólogos para estudos empíricos posteriores. O exercício ontológico laclauniano nos permite compreender o cerne de uma noção, ainda que, respeitando profundamente a ideia do abismo como fundamento, tal cerne não poderá ser visto como uma forma de entificação, visto que ele não se deriva de uma experiência ôntica específica, mas é decorrente mesmo de uma reflexão propriamente ontológica. Esperamos deixar mais claro este ponto na sequência do argumento. Antes, como já enunciamos, passaremos primeiro pela noção central de discurso.

Partamos, assim, do princípio que todos os objetos e ações são dotados de sentido, são significados. A significação, é importante desde já ressaltar, não pode ser considerada como um ato propriamente individual, ou seja, essa não é fruto da consciência esclarecida ou da racionalidade dos indivíduos num sentido cartesiano. A significação é sempre estrutural, ${ }^{5}$ quer dizer, depende de um contexto relacional e negativo: um sentido pode existir somente relacionando-se e diferenciando-se de outro (Saussure, 2006). Assim e de forma simples, a palavra "pai" somente tem sentido se tomada sincronicamente com "mãe", "filho", "filha" e igualmente cada uma dessas pode ser compreendida somente se considerado o contexto linguístico mais geral ligado à palavra "família".

Outra distinção importante para a noção de discurso é a que se refere à diferença entre "existência" e "ser da existência". Para Laclau

\footnotetext{
${ }^{5}$ Saussure já chamava a atenção acerca da inércia coletiva à renovação da língua: "da língua (...) cada qual participa a todo instante e é por isso que ela sofre sem cessar a influência de todos. Esse fato capital basta para demonstrar a impossibilidade de uma revolução. A língua, de todas as instituições sociais, é a que oferece menos oportunidades às iniciativas" (2006, p. 88).
} 
(1990), a existência pressupõe a dimensão realista, a qual nos demonstra as coisas "estão aí" independentemente da nossa vontade. No entanto, tal indubitável materialidade nunca é desprovida de um contexto estrutural e significativo que lhe dá suporte. Dessa forma, um objeto nunca é somente um objeto, mas um objeto imerso em uma estrutura de sentidos. Isto quer dizer que a simples existência de algo não é capaz de exaurir o seu sentido; este depende de um sistema de significantes do qual ele é parte. Um objeto esférico, para usar um exemplo de Laclau (1990), não é somente um objeto esférico, mas uma bola de futebol, que é parte de uma ampla estrutura de significação (bola, jogadores, clubes, torcida etc.). Assim, tudo o que conhecemos possui sentido somente por que está articulado com outros sentidos em uma estrutura discursiva, uma estrutura de fixação de sentidos geradora de estabilidade cognitiva.

Além dos pressupostos acima, é igualmente importante destacar que todo processo de significação é marcado pela contingência e pela precariedade. Isso quer dizer que a forma como significamos o que significamos depende inexoravelmente, como temos visto, de uma estrutura de sentidos que carrega a sua própria historicidade definida de forma contingente, ou seja, dependente de uma constelação de fatores que foram decididos no lugar de outros poderiam ter sido possíveis. Além disso, toda produção de sentidos é sempre precária, marcada por sua própria finitude existencial. Portanto, para que uma significação seja possível, é preciso haver uma estrutura cuja existência é o resultado de um processo que, ainda que não fortuito, não pode ser definido a priori, pois depende da contingência, além de sua existência ser necessariamente precária.

Para avançarmos ainda mais na compreensão de discurso para Laclau, é importante apresentarmos duas noções centrais, sedimentação e reativação. Sedimentação e reativação são noções oriundas da filosofia de Edmund Husserl. No entanto, no contexto de nossa discussão, apresen- 
taremos a leitura realizada pelo filósofo argentino (1990; 2014). Segundo Laclau (2014, p. 3), para Husserl, "ideias sedimentadas são aquelas formas cristalizadas que romperam seus vínculos com a intuição original a partir da qual elas surgiram, enquanto que reativação é a revelação deste vínculo perdido (...)". Laclau não faz qualquer oposição à noção husserliana de sedimentação; sua releitura direciona-se à de reativação: "[P]ara Husserl, o processo de reativação conduz a um sujeito transcendental que é fonte absoluta de sentido; para mim, ele leva a uma instância de contingência radical, na qual muitas outras decisões poderiam ter sido tomadas" (2014, p. 4). Assim, o momento da reativação marca a contingência da produção de toda verdade, da tomada de qualquer decisão, do caráter não natural na forma como as configurações estruturais estão arranjadas em dada circunstância.

Os elementos acima introduzidos (contingência, precariedade, sedimentação e reativação) são fundamentais para compreendermos que todo discurso é resultado da contingência e da historicidade. Vejamos, agora, de uma forma mais sistemática, como o discurso se articula desde a perspectiva da teoria do discurso.

Primeiramente, é fundamental dizer que, para Laclau, discurso não pode ser entendido como o resultado de um conjunto de enunciados, de textos ou de falas, numa dimensão meramente linguística. Evidentemente que a dimensão linguística é central para qualquer discurso, mas este não se esgota simplesmente aí. Neste sentido, discurso é uma categoria que une palavras e ações, que tem natureza material e não mental e/ou ideal (Laclau e Mouffe, 1985). Discurso é prática - daí a ideia de prática discursiva - uma vez que quaisquer ações empreendidas por sujeitos, identidades, grupos sociais são sempre significativas e contêm em si as dimensões de existência e de ser da existência, como acima mencionamos. O social, portanto, é sempre significativo, simbólico, sobredeterminado. 
Tendo em vista a materialidade e a estruturalidade inerentes a todo discurso, para Laclau e Mouffe (1985), um discurso é o resultado de uma prática articulatória e significativa que constitui e organiza relações sociais. Articulação, por sua vez, é uma prática que se estabelece entre elementos que, num primeiro momento, não estão articulados entre si. Podemos dizer, portanto, que no momento anterior ao da articulação, esses elementos estão imersos numa lógica complexa, ou seja, estão dispersos no campo da discursividade. A prática articulatória une esses elementos transformando-os em momentos. Portanto, um elemento, quando ingressa na articulação e em relação a essa, deixa seu status de elemento e assume a condição de momento diferencial. A articulação entre esses momentos diferenciais resulta necessariamente na modificação de suas identidades, ou melhor, numa alteração semântica de seus conteúdos particulares anteriores ao ingresso na prática articulatória. O resultado da prática articulatória é o discurso. Nas palavras de Laclau e Mouffe (1985, p. 105):

No contexto desta discussão, chamaremos articulação toda prática que estabelece uma relação entre elementos de forma que suas identidades são modificadas como resultado da prática articulatória. A totalidade estruturada resultante da prática articulatória, chamaremos discurso. As posições diferenciais, na medida em que elas aparecem articuladas em um discurso, chamaremos momentos. Ao contrário, chamaremos elemento qualquer diferença que não esteja discursivamente articulada (grifos no original).

Apresentamos, em linhas gerais, o discurso, o qual é, para Laclau, "o campo de uma ontologia geral, quer dizer, de uma reflexão acerca do ser enquanto ser" (Laclau, 2008, p. 189 - grifos no original). Como campo de uma ontologia geral, na obra do autor, todas as demais noções - como, por exemplo, as duas que veremos na sequência, hegemonia e populismo -, só fazem sentido se pensadas desde uma perspectiva discursiva. Nossa ideia, a partir de agora, é demonstrar como Ernesto Laclau refletiu 
sobre a política influenciado pela matriz pós-fundacionalista. Tal reflexão, entendemos, é de extrema utilidade, sobretudo para esclarecer noções que muitas vezes são utilizadas no âmbito das ciências sociais, mas, que, devido à sua polissemia, acabam por perder parte significativa de seu potencial heurístico.

Iniciemos, dessa forma, pela noção de hegemonia. Trata-se certamente de uma apropriação dos escritos de Gramsci, mas de uma apropriação realizada no contexto de desconstrução da tradição marxista, operada a partir de Hegemony and Socialist Strategy (Laclau e Mouffe, 1985). ${ }^{6}$ No desenvolvimento da noção de hegemonia, podemos já perceber a presença da diferença ontológica heideggeriana. Primeiramente, vejamos a forma como a noção é apresenta por Laclau para após aduzirmos suas consequências teóricas pós-fundacionais.

Para o autor, hegemonia é o momento em que uma particularidade assume a condição de representação de uma universalidade que lhe é incomensurável (e.g. Laclau e Mouffe, 1985; Laclau, 1990). Tal processo, também chamado pelo autor de "encarnação", 7 só é possível tendo em vista o social estar permanentemente aberto à ressemantização infinita de sentidos, daí a razão pela qual Laclau ter afirmado, em diversas oportunidades, que a sociedade, no sentido de uma totalidade coerente, é uma impossibilidade (e.g. Laclau, 1990). O motivo de o social permanecer aberto, tendo em vista a discussão ontológica realizada neste artigo, já pode ser previsto: Laclau claramente assume, no contexto de sua teoria, que fundamento é essencialmente abismo (Abgrund). Visando estabelecer a relação entre o

\footnotetext{
${ }^{6}$ Tal operação desconstrutiva não poupou o essencialismo classista que ainda persistia na análise gramsciana, a despeito do seu inegável avanço para pensar a hegemonia como uma prática democrática. Nesse sentido, veja-se o capítulo 2 de Hegemony and Socialist Strategy (Laclau e Mouffe, 1985).

${ }^{7}$ Encarnação tem o mesmo sentido de representação tal como este aparece em hegemonia: "encarnação refere-se a uma plenitude ausente que utiliza um objeto diferente de si mesma como meio de representação (...)" (Laclau, 2002, p. 23).
} 
abismo heideggeriano com outros insights do Zeitgeist pós-fundacional, a saber, significante vazio, objeto a (Lacan) e hegemonia, Laclau afirma:

A categoria central aqui é a de Abgrund - um fundamento que é, por sua vez, um abismo. No lugar do fundamento, há um abismo, ou, para ser mais preciso, o próprio abismo é o fundamento. Dizer que o abismo é o fundamento não significa, pura e simplesmente, a ausência de fundamento o que seria apenas uma ausência -, mas antes a presença de uma ausência. ${ }^{8} \mathrm{E}$ essa ausência, enquanto presença, necessita ser representada. (...) É aqui que a diferença ontológica aparece: o conteúdo ôntico não desaparece, mas é distorcido através dessa atividade des-fundante (...) já que não há fundamento último, não há tampouco fixação última de sentido; mas por que este momento de não fixação deve ser representado, ele abre caminho para fixações parciais (...). Em outros termos: a distorção - fixação parcial - é o único meio de representar aquilo que é constitutivamente irrepresentável (2014, p. 146-147 - grifo no original).

Assim, considerar a noção de hegemonia desde essa herança heideggeriana pressupõe tomá-la sempre a partir da contingência e da precariedade, características essenciais do pós-funcionalismo. É justamente por essa razão que o filósofo argentino entende hegemonia como uma particularidade que assume a tarefa de encarnar uma plenitude ausente, mas ao mesmo tempo necessária. Como não há a possibilidade final, do ponto de vista heideggeriano, de um conteúdo ôntico assumir a condição do ser como fundamento último (o que seria a sua entificação), mas como, ao mesmo tempo, o fundamento é requerido, o campo social e político está

\footnotetext{
${ }^{8}$ Notemos, nesse sentido, que a expressão de Laclau, "presença de uma ausência" está no próprio centro da noção de representação como tal (veja-se, a este respeito, Enaudeau, 1999). Assim, como analisaremos a seguir, um processo hegemônico é o de uma representação do incomensurável, no sentido de que um conteúdo ôntico assume uma função ontológica, ou, analogicamente ao objeto a de Lacan, quando um objeto parcial, assume o papel da totalidade, que é a própria elevação de um objeto à dignidade da Coisa, via processo de sublimação (Laclau, 2014, p. 148).
} 
totalmente aberto às experiências ônticas precárias. Por exemplo, em uma sociedade que passa por um regime autoritário, surgem vários pontos de antagonismo contra esse regime. Qual desses elementos assumirá a condição de representação hegemônica dependerá da contingência da articulação dos discursos anti autoritários, a qual nenhum elemento tem a priori a condição de liderança hegemônica. Se pressuposéssemos uma liderança "natural", estaríamos adentrando em um terreno essencialista (esta foi, conforme Laclau, a última fronteira que Gramsci não rompeu em sua teoria da hegemonia), para o qual uma ontologia pós-fundacionalista é totalmente estranha. Além disso, a própria noção de hegemonia não faria mais qualquer sentido, pois ela pressupõe um campo social marcado por discursos hegemônicos e contra hegemônicos que só podem ser admitidos sem o estabelecimento de essências ou de uma sociedade aprioristicamente coerente, tal como a leitura fundacionalista da luta de classes como o motor da história.

A questão que nos cumpre abordar agora, para completarmos nossa discussão acerca da hegemonia, é a da relação entre essa noção e a de diferença ontológica em Heidegger. Sem querer ser demasiadamente exaustivo com argumento já desenvolvido acima, lembramos por hora que entre os planos ontológico e ôntico há um abismo essencialmente irrecuperável. Assim, como o ser não tem qualquer essência ou substância, qualquer experiência política será irremediavelmente precária e limitada em sua existência. Neste sentido, voltemos ao exemplo hipotético anterior acerca das lutas que se articularam contra um regime autoritário. Suponhamos que o sentido hegemônico capaz de encarnar a luta contra esse regime tenha sido o de "democracia". Portanto, em torno da luta maior por democracia outras demandas são articuladas, como, por exemplo: direitos dos trabalhadores, direitos das mulheres, reforma agrária, luta contra a pobreza, entre outras. Num sentido laclauniano, o signifi- 
cante democracia tornou-se o ponto nodal (hegemônico) que representa a luta mais geral contra o autoritarismo. Dito isso, qual foi a apropriação teórica específica que Laclau faz da diferença ontológica heideggeriana?

Para Heidegger, como sabemos, o fundamento existe, mas ele é $A b$ grund. Assim, tendo em vista essa perspectiva, não podemos falar em essência ou em substância da democracia, mas, ainda assim, podemos falar em democracia e em seu fundamento como fundamento ausente. Em nosso exemplo, democracia está ligada à luta contra o autoritarismo, além de estabelecer alguns sentidos positivos a partir da articulação discursiva da qual ela é o polo hegemônico. Como hegemonia é uma operação de estabelecimento de um fundamento (precário), visto que o fundamento parcial não somente é possível como também necessário para a geração de coesão e de ordem social, ela é um conteúdo ôntico que assume a função ontológica de fundamentar o vazio. O vazio, para Laclau, não é um lugar a ser ocupado - no sentido de lugar vazio em Lefort (1991) - mas uma operação discursiva hegemônica: democracia é um significante vazio, um significante sem significado, um puro significante, que assume a tarefa ontológica de um vazio que promete a completude, a emancipação daquela sociedade que vive sob um regime político autoritário. O significante democracia é a distorção, a fixação parcial hegemônica, que representa/encarna a plenitude ausente: a emancipação - impossível, ainda que necessária - daquela sociedade que vive até então sob a égide de um regime autoritário.

Passaremos, neste momento, ao nosso segundo e último exemplo de apropriação teórica do pós-fundacionalismo - sobretudo heideggeriano - por Ernesto Laclau, agora em sua mais recente análise do populismo realizada em On Populist Reason (Laclau, 2005a). Novamente, a questão que importa ao filósofo não é atinente aos tipos ou às características dos populismos que existiram ou que existem, mas à questão mais fundamental: quando falamos em populismo, sobre o que estamos falando exatamente? Ou de forma ainda mais direta: o que é populismo? 
Populismo é uma daquelas categorias que os cientistas sociais utilizam com grande frequência ao mesmo tempo em que está mergulhada em uma polissemia que prejudica a sua própria compreensão. Para Laclau, o erro mais comum de diversos teóricos do populismo está em procurar características ou ideologias próprias para esse fenômeno, pois, para o filósofo argentino, é inútil a tentativa de identificação de "conteúdos universais" ao populismo, a partir de experiências ônticas (Laclau, 2005a, p. 15). Para o autor, coerente com a ideia da diferença ontológica heideggeriana, populismo não é visto como uma categoria ôntica, mas ontológica:

(...) populismo é uma categoria ontológica e não ôntica, isto é, seu sentido não pode ser encontrado em nenhum conteúdo ideológico ou político, a partir da descrição das práticas de qualquer grupo particular, senão um determinado modo de articulação desses conteúdos ideológicos, políticos ou sociais, quaisquer que sejam (...) (Laclau, 2005b, p. 34 - grifos no original).

Se, para Laclau, não podemos efetivamente conhecer a especificidade do populismo a partir dos conteúdos específicos de experiências políticas que têm esse nome, precisamos recorrer aos seus aspectos mais formais e definidores. Assim, sob o seu aspecto ontológico, o populismo está relacionado a "um modo específico de articulação - a prevalência da lógica equivalencial sobre a diferencial - independentemente dos conteúdos reais que são articulados" (Laclau, 2005b, p. 44). Nesta lógica equivalencial, que divide antagonicamente o campo social e político ao meio, o povo, como categoria político-discursiva, é central: o populismo é a construção política de um povo contra os seus inimigos. Essa forma de construção é a especificidade ontológica do populismo, a qual está presente em qualquer experiência política que leva esse nome, seja agrária seja urbana, seja de direita seja de esquerda. Notemos ainda que não há, nesta construção laclauniana, a assunção de qualquer elemento ôntico 
particular, característica ou ideologia: o populismo não pode ser ontologicamente compreendido a partir de um conteúdo específico, mas tão somente por sua forma específica de articulação política.

A construção do povo, como elemento da ontologia do populismo, não tem, como vimos, qualquer prioridade sociológica ou ideológica. $\mathrm{O}$ povo é uma construção discursiva e hegemônica que pode assumir onticamente uma série de formas. O ponto central é o da construção do povo. Tal construção, segundo Laclau, orientado mais uma vez por uma perspectiva heideggeriana, é exitosa quando uma parte (a plebs) assume a condição de populus, o que é o mesmo que dizer que o conteúdo ôntico encarna o valor ontológico. A tarefa do povo é, novamente contra Lefort (1991), não ocupar um lugar vazio, como um espaço específico em uma dada estrutura, mas produzir uma identidade coletiva popular que é em si vazia. Esse vazio é constituído a partir de uma lógica hegemônica, a qual será mais bem sucedida quanto mais ampla for a cadeia das demandas por ela articuladas. Além disso, o vazio não significa um "sem sentido", mas ao contrário: é um significante que assume a condição de representação das mais diversas reivindicações inscritas nessa estrutura discursiva popular; ele tem de ser vazio para justamente poder representar uma plenitude ausente.

\section{Considerações}

Três foram os objetivos centrais deste artigo. Com referência ao primeiro, discorremos sobre o que chamamos de o "Zeitgeist pós-fundacional", em especial a ênfase na diferença ontológica e no fundamento como Abgrund oriundos da obra de Martin Heidegger. Para cumprir nosso segundo objetivo, discutimos a incorporação e a aplicação da ontologia abissal heideggeriana na obra de Jacques Derrida e, na sequência, na de Ernesto Laclau, principalmente a partir das noções de hegemonia e de populismo. 
O terceiro objetivo reside em verificar a importância e o potencial teórico e analítico que o pós-fundacionalismo tem para pesquisas na área das ciências sociais. Podemos resumir sua relevância em dois pontos: precisão conceitual e a contingência dos fenômenos sociais.

Sobre a precisão conceitual. Como vimos na utilização laclauniana dos elementos ontológicos de Heidegger, a reflexão ontológica permite ao pesquisador ter uma visão, primeiramente formal de um fenômeno, o que significa isolar tais características capazes de serem o ponto de partida para análises empíricas mais refinadas. Voltemos, por exemplo, à concepção laclauniana de populismo. O populismo é normalmente teorizado de forma frágil (e negativa), o que faz com que boa parte de suas noções até hoje construídas, tendo por base experiências ônticas, não sejam capazes de serem heuristicamente explicativas. A solução teórica ontológica laclauniana resolve, em nosso entendimento, a reductio ad absurdum que envolve a história das teorizações deste fenômeno. A obra de Laclau pode ser entendida, nesse sentido, como um exitoso empreendimento de refinamento conceitual de diversas categorias. Além das que tratamos acima, podemos mencionar ainda antagonismo, lógicas da diferença e da equivalência entre outras. Tal abordagem teórica tem sido particularmente útil para análises empíricas transdisciplinares nela fundamentadas. Dito de forma simples: conhecer o "ser" de um fenômeno a partir de uma ontologia não entificante como a heideggeriana, nos abre a possibilidade de vermos, com mais precisão, as sutilezas das experiências ônticas que são objetos de nossas análises.

Acerca da contingência dos fenômenos sociais. Partir da ontologia do fundamento como abismo nos propicia compreender que estruturas sociais, culturais e políticas são em si precárias e dependentes de um contexto político discursivo de constituição. Assim, nada pode ser justificado a priori desde um fundamento exterior, um "centro" que não joga o jogo 
da estruturalidade, como vimos em Derrida. A justificativa da sedimentação de uma verdade nunca está, portanto, além de sua própria configuração discursiva, que se tornou verdade não por ser em si verdade, mas por ter tornado-se hegemonicamente o sentido de verdade: o ôntico que assumiu a condição provisória do ontológico.

Partir de uma epistemologia do Abgrund torna o pesquisador livre de pré-conceitos científicos ou sociais para olhar o seu objeto de pesquisa desde a sua própria perspectiva. A vantagem do abismo epistemológico está justamente nesta radical liberdade de pensar o objeto a partir dele mesmo, a partir de sua própria lógica: uma lógica da lógica. Do ponto de vista da estratégia política, esta radical liberdade abissal nos autoriza a pensar mundos novos, mas, sobretudo, ter a certeza de que novos mundos são possíveis.

Daniel de Mendonça - Doutor em Ciência Política pela Universidade Federal do Rio Grande do Sul. Professor Associado na Universidade Federal de Pelotas (UFPel). $\$ ddmendonca@gmail.com

Bianca de Freitas Linhares - Doutora em Ciência Política pela Universidade Federal do Rio Grande do Sul. Professora Auxiliar na Universidade Federal de Pelotas (UFPel). $\gg$ bipolitica@hotmail.com

Sebastián Barros - Doutor em Ciência Política pela Universidade de Essex, Inglaterra. Professor Titular de Sociologia na Universidade Nacional da Patagônia San Juan Bosco (UNPSJB), Argentina. $\longrightarrow$ barros.sebastian@gmail.com 
Sociologias, Porto Alegre, ano 18, no 41, jan/abr 2016, p. 164-194

\section{Referências}

1. ABbagnanO, N. Dicionário de Filosofia. São Paulo: Martins Fontes, 2000.

2. CASANOVA, M. A. Compreender Heidegger. 5ํㅡㄹ ed. Petropolis: Vozes, 2015.

3. DERRIDA, J. A Escritura e a Diferença. 3a ed. São Paulo: Perspectiva, 2002.

4. DOSSE, F. História do Estruturalismo (vol. I): o campo do signo. Bauru: EdusC, 2007.

5. ENAUDEAU, C. La Paradoja de la Representación. Buenos Aires: Paidós, 1999.

6. HEIDEGGER, M. Ontologia: hemernêutica da faticidade. 2ª ed. Petrópolis, Vozes, 2013.

7. HEIDEGGER, M. A Essência do Fundamento. Lisboa: Edições 70, 2007.

8. HEIDEGGER, M. Que é isto, a Filosofia?: identidade e diferença. Petrópolis: Vozes, 2006.

9. HEIDEGGER, M. Ser e Tempo. 11aa ed. (Partes I e II). Petrópolis: Vozes, 2002.

10. HEIDEGGER, M. O Princípio do Fundamento. Lisboa: Instituto Piaget, 2000.

11. HOWARTH, D. Discourse. Berkshire: Open University Press, 2000.

12. LACLAU, E. Los Fundamentos Retóricos de la Sociedad. Buenos Aires: Fondo de Cultura Económica, 2014.

13. LACLAU, E. On Populist Reason. London: Verso, 2005a.

14. LACLAU, E. Populism: what's in a name? In: PANIZZA, Francisco (Ed.). Populism and the Mirror of Democracy. London: Verso, $2005 \mathrm{~b}$.

15. LACLAU, E. Posfácio. In: MENDONÇA, D.; RODRIGUES, L.P. (Orgs.). PósEstruturalismo e Teoria do Discurso: em torno de Ernesto Laclau. Porto Alegre, EdiPUCRS, 2008. pp. 189-191.

16. LACLAU, E. Misticismo, Retórica y Política. Buenos Aires: Fondo de Cultura Económica, 2002.

17. LACLAU, E. Emancipation(s). London: Verso, 1996.

18. LACLAU, E. Nuevas Reflexiones sobre la Revolución de nuestro Tiempo. Buenos Aires: Nueva Visión, 1990.

19. LACLAU, E; MOUFFE, C. Posmarxismo sin pedido de disculpas. In: LACLAU, E. Nuevas Reflexiones sobre la Revolución de nuestro Tiempo. Buenos Aires: Nueva Visión, 1990. 
20. LACLAU, E; MOUFFE, C. Hegemony and Socialist Strategy: towards a radical democratic politics. London: Verso, 1985.

21. LEFORT, C. Pensando o Político: ensaios sobre democracia, revolução e liberdade. Rio de Janeiro: Paz e Terra, 1991.

22. LÉVI-STRAUSS, C. Antropologia Estrutural. São Paulo: Cosac Naify, 2012.

23. LÉVI-STRAUSS, C. Estruturalismo e crítica. In: COELHO, E.P. (Org.). Estruturalismo: antologia de textos teóricos. Lisboa: Portugália Editora, 1968. pp. 393396 .

24. MARCHART, O. Post-Foundational Political Thought: political difference in Nancy, Lefort, Badiou and Laclau. Edinburgh: Edinburgh University Press, 2007.

25. MENDONÇA, D; RODRIGUES, L. P. (Orgs.). Pós-Estruturalismo e Teoria do Discurso: em torno de Ernesto Laclau. Porto Alegre, EdiPUCRS, 2008. pp.189191.

26. RÉE, J. Heidegger: história e verdade em Ser e Tempo. São Paulo: Editora UNESP, 2000.

27. SAUSSURE, F. Curso de Lingüística Geral. São Paulo: Cultrix, 2006.

28. TORFING, J. New Theories of Discourse: Laclau, Mouffe and Zizek. Oxford: Blackwell, 1999.

29. WILLIAMS, J. Pós-Estruturalismo. 2a ed. Petrópolis: Vozes, 2013.

Recebido em: 28/12/2015

Aceite final em: 22/02/2016 